\title{
Resíduos volumosos no município de São Paulo: gerenciamento e valorização
}

\author{
Bulky waste in the municipality of São Paulo: management and valuation
}

Marcia Harumi Ito[a], Renata Colombo[a] (1)

[a] Universidade de São Paulo (USP), Escola de Artes, Ciências e Humanidades, São Paulo, SP, Brasil

Como citar: Ito, M. H., \& Colombo, R. (2019). Resíduos volumosos no município de São Paulo: gerenciamento e valorização. urbe. Revista Brasileira de Gestão Urbana, v. 11, e20180117. https://doi.org/10.1590/21753369.011.e20180117

\section{Resumo}

O tratamento e a destinação dos resíduos sólidos ocorrem de diferentes formas mediante o desenvolvimento econômico, tecnológico e cultural de cada país. No Brasil, apesar das diversas legislações regulamentando o gerenciamento destes resíduos, vários impactos socioambientais têm sido constatados e associados ao descarte irregular e/ou inadequado dos mesmos. Entre os resíduos que possuem uma complexa problemática de gestão e possibilidade de aperfeiçoamento estão os resíduos sólidos volumosos. Neste estudo realizou-se uma análise do modelo atual de gerenciamento dos resíduos volumosos no município de São Paulo, com apontamento para os pontos críticos e propostas de diretrizes para um gerenciamento mais adequado do ponto de vista socioambiental. Os dados do modelo atual foram obtidos a partir da coleta de informações públicas e visitas in loco aos Ecopontos do município. Os resultados indicam a falta de gerenciamento de alguns resíduos volumosos pelos Ecopontos e que os resíduos que são recebidos por estas unidades são atualmente dispostos em aterros podendo ter direções de valorização. Destaca-se também a falta de programas de Educação Ambiental e uma má qualidade da segregação na fonte. As diretrizes de gerenciamento e valorização propostas estão baseadas nos modelos em funcionamento no exterior e em sistemas de reaproveitamento, preconizados nas legislações Brasileiras.

Palavras-chave: Gerenciamento. Resíduos sólidos. Ecopontos. Resíduos volumosos.

\section{Abstract}

The treatment and the disposal of solid wastes occur in different ways through the economic, technological and cultural development of each country. In Brazil, despite the various legislations regulating the management of these wastes, several socio-environmental impacts have been found associated with the irregular and/or inappropriate disposal of these wastes. Among the wastes that have a complex problem of management and the possibility of improvement are the bulky wastes. In this study, an analysis of the current model of management of the bulky waste in the municipality of São Paulo was carried out, aiming at the critical points and proposals of guidelines for more appropriate management

MHI é gestora ambiental, bacharela em Gestão Ambiental, e-mail: marcia.harumi.ito@usp.br

RC é química, bacharela em Química, e-mail: renatacolomb@gmail.com 
of the socio-environmental point of view. The data of the current model were obtained from the collection of public information and on-site visits to the Ecopoints of the municipality. The results indicate the lack of management of some bulky wastes by the Ecopoints and that the wastes that are received by these units are currently disposed in landfills and may have directions of valorization. It also highlights the lack of environmental education programs and a low quality of segregation at the source. The proposed management and valorization guidelines are based on models operating abroad and in reutilization system proposed in Brazilian legislation.

Keywords: Management. Solid waste. Ecopoints. Bulky waste.

\section{Introdução}

O intenso processo de industrialização, bem como o acelerado crescimento demográfico e urbano que vem ocorrendo nas últimas décadas, têm ocasionado um aumento no consumo de produtos e consequentemente na produção de resíduos sólidos diversos. Estes resíduos vêm ganhando significativa importância devido aos potenciais impactos socioambientais diretos e indiretos que eles podem causar, especialmente quando descartados de forma irregular (Ferreira \& Anjos, 2001; Jacobi \& Besen, 2006; Jacobi \& Besen, 2011; Gouveia, 2012; Pinhel, 2013).

Os resíduos descartados sem critérios de destinação ambientalmente adequados, além de elevar os custos municipais com sua coleta, transporte e destinação final, ainda geram diversos inconvenientes e/ou risco à saúde humana e ao meio ambiente (Ferreira \& Anjos, 2001; Karpinsk et al., 2009; Jacobi \& Besen, 2011, Gouveia, 2012). A contaminação do solo, águas e ar é um dos principais problemas que os resíduos sólidos vêm ocasionando e é gerada tanto pelos resíduos orgânicos quanto pelos diversos outros tipos de resíduos produzidos atualmente. 0 avanço da tecnologia na geração de produtos descartáveis e com maior tempo de degradabilidade, vem tornando a gestão destes resíduos ainda mais complexa (Giusti, 2009; Gouveia, 2012).

Nesse sentido, diversos países têm se destacado com políticas e tecnologias para o processamento de seus resíduos sólidos. A Alemanha é um dos países que possui um dos índices mais elevados de reaproveitamento do mundo e objetiva até o final desta década, a recuperação completa e de alta qualidade dos resíduos sólidos urbanos, reduzindo a zero a necessidade da destinação aos aterros sanitários (EEA, 2009). Esses avanços se devem em grande parte à sua política de gerenciamento dos resíduos sólidos baseada no fechamento dos ciclos (política de economia circular), onde os resíduos são tratados visando à conversão em matérias-primas e energia (EEA, 2009; Jaron \& Kossmann, 2018; Fricke et al., 2015). 0 Japão também faz parte dos países com um dos mais avançados modelos de gerenciamento de resíduos do mundo. A sua Lei de Gestão de Resíduos instituída em 1970, foi o primeiro passo em direção ao atual sistema, que envolve toda a cadeia de produção e destinação do lixo, a partir dos conceitos de reduzir, reciclar e reaproveitar. Em 1995 foi decretada uma lei que incentiva a coleta seletiva e a reciclagem, o que fez o país investir em alta tecnologia também para o reaproveitamento de resíduos (Jucá et al., 2012; Yolin, 2015). Os princípios deste gerenciamento envolvem desde o planejamento e extração da matéria-prima até o desmonte/reuso do produto e o descarte do resíduo, considerando todo o ciclo de serviços e produtos (EEA, 2009; Yolin, 2015). Nos demais países, sobretudo nos países em desenvolvimento, o gerenciamento dos resíduos ainda se defronta com rigorosas limitações, sem muito controle e investimentos públicos e/ou privados. No Brasil o processo de destinação dos resíduos sólidos ocorre prioritariamente por meio da disposição em lixões, aterros comuns e sanitários. Iniciativas de regulamentação da coleta seletiva, responsabilidade compartilhada e incentivos à gestão integrada de resíduos começaram a serem propostas somente em 2010, através da promulgação da Política Nacional de Resíduos Sólidos (PNRS), instituída pela Lei no 12.305/2010 (Giusti, 2009; Brasil, 2010; Jacobi \& Besen, 2011; ABRELPE, 2016; Silva, 2016; MMA, 2017). 
Para atingir as metas preconizadas na PNRS uma das primeiras etapas é a classificação adequada dos resíduos sólidos. Diversas normas e legislações federais, estaduais e municipais estão em vigor no país atualmente classificando estes resíduos quanto à sua origem, características químicas e físicas e grau de periculosidade ou riscos ao meio ambiente e à saúde humana. Dentre os diversos tipos de resíduos existentes, este trabalho foca nos resíduos classificados como resíduos volumosos (RV). Na esfera do município de São Paulo, estes resíduos estão regulamentados pela Lei no 14.803, de 26 de junho de 2008 em consonância com a Resolução CONAMA no 307/2002. Os resíduos volumosos, segundo esta lei, são constituídos por materiais de grandes dimensões que não são removidos pelo sistema de coleta pública convencional, tais como mobiliários, equipamentos domésticos de grande porte, grandes embalagens, madeiras de diversas origens, resíduos vegetais (resultantes de podas e serviços semelhantes) e outros resíduos não provenientes de processos industriais (Brasil, 2002; São Paulo, 2008). Entre os equipamentos domésticos, estão aqueles de grande porte como geladeira, fogão, televisão, lavadoras de roupa e louça, entre outros. Grandes embalagens são caracterizadas por tonéis, embalagens de grandes equipamentos, contêiners, caixas (papelão, madeira e plásticos) de grandes dimensões, entre outros. Dentre as peças de madeira, estão as casas de madeira pré-fabricadas, venezianas, peças para instalações, artefatos de tanoaria, embalagens de madeira, material trançado, palha, cortiça, entre outros (ABNT, 2004).

Os RV são comumente considerados de baixa periculosidade, sendo que o principal impacto ambiental relacionado a eles se refere ao grande volume gerado e ocupado nos aterros onde são destinados. No entanto, conforme a NBR 10.004/2004, estes resíduos podem ser enquadrados como Classe II A (não perigosos e não inertes), pois possuem propriedades de biodegradabilidade, combustibilidade ou solubilidade em água. Dependendo da sua composição podem ainda serem enquadrados como Classe I (perigosos). Este é o caso de resíduos que contém tintas, colas, vernizes ou outros produtos químicos (ABNT, 2004). Adicionalmente, os RV em geral possuem formatos e propriedades físicas que facilitam a retenção de água e o surgimento de criadouros, gerando a proliferação de insetos, como o mosquito Aedes Aegypti, e vetores de doenças que colocam em risco a saúde da população (Pinto, 1999; Karpinsk et al., 2009; Fernandez, 2012).

De acordo com a Lei no 14.803 , estes resíduos devem ser encaminhados às Áreas de Transbordo e Triagem de Resíduos da Construção Civil e de Resíduos Volumosos (ATT). As ATT se configuram como estabelecimentos privados voltados à destinação dos resíduos de grandes e pequenos geradores. Os geradores de volumes acima de $1 \mathrm{~m}^{3}$ encaminham os RV diretamente às ATT, pagando "os" devidos tributos por este serviço. Os que geram volumes inferiores devem destinar seus RV aos Pontos de Entrega para pequenos volumes ou Estação de Entrega Voluntária de Inservíveis que, após a coleta e triagem, são encaminhados à adequada disposição (São Paulo, 2008; Prefeitura de São Paulo, 2014).

Os Pontos de Entrega para Pequenos Volumes ou Estação de Entrega Voluntária de Inservíveis (também denominados no município de São Paulo de Ecopontos), são áreas públicas e de entrega gratuita, que gerenciam o recebimento, armazenamento, transporte e destinação final de resíduos recicláveis, entulho e resíduos volumosos limitados ao volume de até $1 \mathrm{~m}^{3}$. A disposição dos entulhos e resíduos volumosos ocorre por meio da separação em caçambas diferenciadas para cada tipo de resíduo (Jacobi \& Besen, 2011; AMLURB, 2017). A acomodação dos recicláveis acontece em contêineres verdes fechados com capacidade para 2.500 litros cada, também conhecidos como Ponto de Entrega Voluntária (PEV) (Prefeitura de São Paulo, 2014).

A implantação dos Ecopontos no município de São Paulo está regulamentada pelo decreto $\mathrm{n}^{\circ} 55.113$, de 15 de maio de 2014 (São Paulo, 2014). A regulação, fiscalização e competência para elaborar as condições e detalhar a operação dos Ecopontos no município de São Paulo são do órgão regulador dos serviços de limpeza urbana da cidade, a Autoridade Municipal de Limpeza Urbana (AMLURB) (Prefeitura de São Paulo, 2014).

Atualmente existem 100 Ecopontos implantados no município de São Paulo, sendo que os serviços prestados são realizados por empresas privadas através de contratos de serviço (AMLURB, 2017). Na atualidade, os Ecopontos do município são gerenciados por dois grupos de empresas organizadas 
em consórcios. O consórcio Soluções e Meio Ambiente (SOMA) gerencia um total de 50 Ecopontos (SOMA, 2013) e o Consórcio São Paulo Ambiental (INOVA) é responsável pelo gerenciamento de 50 Ecopontos (Inova, 2017).

Apesar da existência das ATT, Ecopontos e de outros programas públicos visando à disposição correta dos resíduos sólidos volumosos, estes resíduos ainda são frequentemente dispostos em lugares irregulares. Terrenos baldios, construções abandonadas e calçadas são os locais usualmente mais afetados por esta disposição irregular. A prática recorrente deste descarte ilegal por parte de empresas, moradores e pequenos transportadores de resíduos de construção civil, mesmo após sucessivos recolhimentos destes resíduos pelos órgãos responsáveis pela limpeza urbana, configura os chamados pontos viciados. A eliminação dos pontos viciados tem sido um grande desafio para o poder público nos últimos anos (Prefeitura de São Paulo, 2014; AMLURB, 2017).

Dentro deste contexto, percebe-se que novas diretrizes são necessárias para que o processo de gestão destes resíduos possa ser realizado de forma mais eficaz, minimizando os impactos socioambientais gerados atualmente e contribuindo com os objetivos preconizados na PNRS de uma gestão integrada e sustentável (Brasil, 2010).

\section{Parte experimental}

Este trabalho iniciou-se através de uma consulta pública a respeito do nível de conhecimento da população em relação aos procedimentos de descarte dos resíduos volumosos, bem como o grau de disseminação das informações sobre a existência e o funcionamento dos Ecopontos. 0 levantamento foi realizado através da aplicação de um questionário, com participantes não identificados (Brasil, 2016; Rudio, 2001), à pessoas de diferentes idades, sexos, escolaridade, profissões, residentes na Região Metropolitana, bem como no município de São Paulo. 0 questionário foi aplicado também à comunidade (alunos, docentes e funcionários) da Escola de Artes, Ciências e Humanidades da Universidade de São Paulo (EACH/USP), devido à sua diversidade cultural, econômica e intelectual, ao potencial de disseminação da pesquisa e por se tratar de uma unidade de ensino que contempla cursos direcionados para a gestão e sustentabilidade ambiental. 0 questionário semiestruturado (Apêndice A) foi elaborado e disponibilizado para preenchimento por dois meios de divulgação. Um deles foi o meio eletrônico, através da sua elaboração na ferramenta gratuita e online Google Forms (Plataforma Google) e divulgação via redes sociais (grupos do Facebook, Whatsapp e correio eletrônico). Outro meio foi a elaboração do questionário impresso e sua disponibilização em locais públicos acompanhado do respectivo coletor de respostas, visando atingir o público que não faz a utilização dos meios digitais. No total foram realizadas 505 consultas.

Posteriormente, deu-se início ao levantamento de dados a cerca do atual processo de funcionamento/gerenciamento dos resíduos volumosos nos Ecopontos do município de São Paulo. Estes dados foram obtidos através de visitas in loco e entrevistas semiestruturadas (May, 2001; Boni \& Quaresma, 2005) com funcionários e gestores do local. As visitas in loco foram realizadas em 30 Ecopontos do município de São Paulo, sendo eles: Tereza Cristina, Santa Cruz, Imigrantes, Jabaquara, Mirandópolis, Vila Mariana, Saioá, Anhaia Mello (todos gerenciados pela Consórcio SOMA) e Cambuci, Liberdade, Armênia, Vila Madalena, Água Rasa, Pari, Viaduto Antártica, Vila Jaragua, Vila Guilherme, Vila Maria,Tatuapé, Bresser, Brás, Moóca, Belém, Parque Peruche, Politécnica, Pinheiros, Alto de Pinheiros, Barra Funda, Tucuruvi e Santana (gerenciados pelo Consórcio Inova). Foram realizadas também, visitas em 3 Ecopontos da mesorregião metropolitana de São Paulo, localizados em Mogi das Cruzes: Ecopontos Jundiapeba, Parque Olímpico e Jardim Armênia. As entrevistas foram realizadas com o responsável técnico da AMLURB e com os responsáveis técnicos pela gestão de resíduos sólidos da Secretaria do Verde e Meio Ambiente e da Secretaria Municipal de Serviços Urbanos (ambas da Prefeitura Municipal de Mogi das Cruzes). 0 responsável técnico da Secretaria do Verde e Meio Ambiente é responsável pela gestão do Ecoponto 
Jundiapeba e o responsável técnico da Secretaria Municipal de Serviços Urbanos, responsável pela gestão dos Ecopontos Parque Olímpico e Jardim Armênia.

As diretrizes de gestão propostas foram baseadas em um levantamento bibliográfico a cerca dos modelos existentes em países com severa política de gestão de resíduos e também nas diretrizes de gestão preconizadas nas legislações brasileiras, tal como a PNRS (Brasil, 2010). Todos os dados e informações obtidas, foram processados pela análise crítica do atual gerenciamento, utilizando-se da triangulação dos dados (Adorno \& Castro, 1994).

Como parâmetro de aferição e avaliação das diretrizes propostas, foram elaborados indicadores de desempenho ambiental para gestão municipal de RV, baseados em metodologias internacionais e nacionais publicadas nas literaturas Campos \& Melo (2008) e Milanez (2002) modificado por Polaz \& Teixeira (2009).

\section{Resultados e discussão}

\section{Resíduos Volumosos e Ecopontos: consulta pública}

Os resultados da consulta pública sobre o nível de conhecimento da população em relação aos procedimentos de descarte dos resíduos volumosos e funcionamento dos Ecopontos demonstrou que 53\% dos respondentes possuem conhecimento do termo "Resíduos Volumosos", 81\% afirmaram ter conhecimento do que são Ecopontos e $64 \%$ sabem quais os tipos de resíduos que podem ser descartados nestes locais. Embora a maioria dos entrevistados tenha afirmado conhecer o que são Ecopontos observou-se falta de clareza quanto à diferença de Pontos de Entrega Voluntária e Ecopontos, demonstrando que o conhecimento sobre o local correto de descarte dos RV não está muito bem difundido.

Notou-se que, para ambos os conceitos, não houve preponderância de conhecimento entre o sexo feminino e masculino. A profissão e o grau de escolaridade também não se demonstrou um fator determinante para este conhecimento, uma vez que as respostas foram dispersas entre os participantes de diferentes ramos profissionais e formação acadêmica. 0 meio social com maior disseminação das questões ambientais, no entanto, demonstrou influenciar no nível de conhecimento dos entrevistados sobre os referidos conceitos. Os entrevistados pertencentes à comunidade EACH-USP demonstraram possuir um grau de conhecimento ligeiramente mais elevado sobre os procedimentos de descarte e funcionamento dos Ecopontos do que os demais entrevistados.

A faixa etária foi outro fator que também demonstrou influenciar no grau de conhecimento do assunto. Na faixa de 30 a 59 anos, $57 \%$ dos entrevistados demonstrou conhecimento sobre resíduos volumosos e $55 \%$ conhecimento sobre o funcionamento dos Ecopontos em comparação com $35 \%$ e $38 \%$, respectivamente, dos entrevistados na faixa etária de 18 a 29 anos. Em relação aos tipos de resíduos que são coletados nos Ecopontos, 57\% dos entrevistados entre 30 a 59 anos demonstraram ter conhecimento sobre o assunto em comparação a 35\% dos que possuem a faixa etária de 18 a 29 anos. Esse conhecimento pode estar correlacionado com a responsabilidade de descarte dos resíduos, uma vez que $57 \%$ dos entrevistados na faixa etária de 30 a 59 anos afirmaram utilizar os Ecopontos para o descarte de seus resíduos, enquanto somente 34\% dos entrevistados entre 18 a 29 anos já fez o descarte de resíduos neste local. Quanto à utilização destes locais pelos entrevistados, $66 \%$ relataram que os Ecopontos estão localizados distantes de suas residências. Estes resultados sinalizam uma falha de acessibilidade a estes locais para a correta disposição destes resíduos.

Acerca dos pontos que podem ser melhorados nos Ecopontos, 91\% dos entrevistados apontam a divulgação, seguido de $44 \%$ apontando a logística (menor deslocamento) de descarte como os principais fatores. Foram sugeridos que os Ecopontos estejam localizados em pontos mais acessíveis e com maior visibilidade à população, que sejam promovidos programas de incentivo aos carroceiros e 
munícipes para o descarte nos Ecopontos, que haja melhorias no canal de atendimento via telefone (evitando fornecimentos de informações equivocadas e morosidade na resolução de dúvidas/problemas), aumento no volume máximo permitido para a disposição no Ecoponto e também a existência de funcionários no local que auxiliem na descarga (transporte) dos resíduos até as caçambas.

\section{Ecopontos: cenário atual de funcionamento}

Dados do Plano de Gestão Integrada de Resíduos Sólidos da Cidade de São Paulo (PGIRS) de 2014 mostram que os RV estão caracteristicamente presentes nos materiais que são dispostos irregularmente no município (Prefeitura de São Paulo, 2014). Dados divulgados pela SOMA e Inova mostram que a quantidade de RV recolhidos nos Ecopontos no primeiro semestre de 2017 aumentou em 60,5 mil toneladas (+41,7\%) em relação ao mesmo período do ano anterior e que a quantidade de resíduos somente no mês de Julho de 2017 foi de 31,9 mil toneladas sob 27,5 mil toneladas $(+16,0 \%)$ em julho de 2016 (AMLURB, 2017). O PGIRS mostra ainda que os Ecopontos localizados nas Zonas Centro e Oeste recebem mais RV do que os da Zona Leste e Sul (Prefeitura de São Paulo, 2014).

Com base neste panorama, foram realizadas visitas in loco em Ecopontos de cada uma das zonas do município de São Paulo, com ênfase pra aqueles localizados nas Zonas Centro e Oeste devido ao maior recebimento de RV, objeto deste estudo. Neste estudo, foram incluídos também, os Ecopontos de Mogi das Cruzes visando verificar o funcionamento destes locais na mesorregião metropolitana de São Paulo.

Na Figura 1, encontram-se as informações sintetizadas, referentes ao funcionamento/gerenciamento destes Ecopontos. Conforme pode ser observado nesta síntese, apesar do método de gestão estar incorporado com as diretrizes preconizadas na PNRS (como, por exemplo, as parcerias com cooperativas de reciclagem, empresas e ONGs para a segregação e aproveitamento dos resíduos recicláveis e/ou passíveis de aproveitamento), diversos problemas de gestão ainda são observados. Entre eles está a ausência de processos de valorização dos RV (Prefeitura de São Paulo, 2014).

Outros problemas relevantes são: o descarte de resíduos não permitidos; a má segregação na fonte, resultando em misturas de resíduos perigosos, como lâmpadas entre os RV; falta de compreensão e cooperação dos munícipes quanto às regras de gerenciamento destes locais (com destaque para a insistência em descartar resíduos não permitidos); dificuldade na alocação dos RV pelos munícipes nas caçambas; impossibilidade de receber pneus (mesmo que haja a demanda para o descarte) e necessidade de melhor aproveitamento dos RV. 


\begin{tabular}{|c|c|c|c|c|}
\hline Municípios & \multicolumn{2}{|c|}{ Säo Paulo (50 Ecopontos) } & \multicolumn{2}{|c|}{ Mogi das Cruzes (3 Ecopontos) - Consórcio CSBrasil } \\
\hline Ecopontos & \begin{tabular}{|} 
Consórcio SOMA \\
50 Ecopontos \\
\end{tabular} & $\begin{array}{r}\text { Consórico INOVA } \\
50 \text { Ecopontos } \\
\end{array}$ & $\begin{array}{r}1^{\circ} \text { Ecoponto JD Armênia e } \\
2^{\circ} \text { Ecoponto PQ } \\
\end{array}$ & $3^{\circ}$ Ecoponto Jundiapeba \\
\hline $\begin{array}{l}\text { Tipos de } \\
\text { resíduos } \\
\text { permitidos }\end{array}$ & $\begin{array}{l}\text { Resíduos da construção civil } \\
\text { (RCC); Móveis; Restos de } \\
\text { poda de árvore e madeiras; } \\
\text { Recicláveis Secos (papel, } \\
\text { papelão, vidro e aluminio). }\end{array}$ & $\begin{array}{l}\text { RCC; Móveis; Restos de } \\
\text { poda de árvore e } \\
\text { madeiras; Recicláveis } \\
\text { secos. }\end{array}$ & $\begin{array}{c}\text { RCC; Equipamentos } \\
\text { domésticos e móveis; Lixo } \\
\text { eletrônico; Pneus; Lâmpadas; } \\
\text { Recicláveis Secos; Óleo de } \\
\text { cozinha; Sucata e outros } \\
\text { (descartados } \\
\text { inadequadamente causam } \\
\text { impactos socioambientais). }\end{array}$ & $\begin{array}{l}\text { RCC; Equipamentos domésticos } \\
\text { e móveis; Lixo eletrônico; Pilhas e } \\
\text { baterias; Ferro; Pneus; Latas de } \\
\text { tinta/verniz; Óleo de cozinha; } \\
\text { Lâmpadas e outros (descartados } \\
\text { inadequadamente causam } \\
\text { impactos socioambientais). }\end{array}$ \\
\hline $\begin{array}{l}\text { Quantidade } \\
\text { recebida }\end{array}$ & \multicolumn{2}{|c|}{ Total de $1 \mathrm{~m}^{3}$ por municipe/dia. } & \multicolumn{2}{|c|}{$\begin{array}{l}\text { Total de } 1 \mathrm{~m}^{3} \text { por munícipe/dia. Até } 5 \text { pneus e } 4 \text { lâmpadas por } \\
\text { munícipe/dia. Recicláveis secos e óleo de cozinha sem limitação. }\end{array}$} \\
\hline $\begin{array}{l}\text { Tipos de } \\
\text { resíduos não } \\
\text { permitidos }\end{array}$ & $\begin{array}{l}\text { Residuos domiciliar, } \\
\text { hospitalar, industrial, elétrico e } \\
\text { eletrônico; Gesso; Óleo; } \\
\text { Lâmpadas; Pilhas e baterias; } \\
\text { Amianto; Tonner; Latas de } \\
\text { tinta; Pneus. }\end{array}$ & $\begin{array}{l}\text { Residuos domiciliar, } \\
\text { hospitalar, industrial, } \\
\text { elétrico e eletrônico; } \\
\text { Pilhas e baterias; Óleo; } \\
\text { Gesso; Telhas de } \\
\text { Amianto; Tonner; Latas } \\
\text { de tinta; Lâmpadas. }\end{array}$ & $\begin{array}{l}\text { Residuos industrial, } \\
\text { domiciliar e hospitalar; } \\
\text { Animais mortos e tecidos. }\end{array}$ & $\begin{array}{l}\text { Recicláveis secos; Residuos } \\
\text { industrial, domiciliar e hospitalar; } \\
\text { Animais mortos. }\end{array}$ \\
\hline $\begin{array}{c}\text { Horário de } \\
\text { funcionamento }\end{array}$ & \multicolumn{2}{|c|}{$\begin{array}{l}\text { Segunda a sábado: } 8 \mathrm{~h}-22 \mathrm{~h} \\
\text { Domingo e feriados: } 8 \mathrm{~h}-18 \mathrm{~h}\end{array}$} & $\begin{array}{l}\text { Segunda a sábado: } 08 \mathrm{~h}-18 \mathrm{~h} . \\
\text { Domingos e feriados fechado. }\end{array}$ & $\begin{array}{l}\text { Segunda; quarta a sexta: } 8 \mathrm{~h}-18 \mathrm{~h} \text {. } \\
\text { Terça e sábado: } 7 \mathrm{~h}-14 \mathrm{~h} \text {. } \\
\text { Domingos e feriados fechado. }\end{array}$ \\
\hline $\begin{array}{l}\text { Procedimento } \\
\text { de entrega }\end{array}$ & \multicolumn{2}{|c|}{$\begin{array}{l}\text { Preenchimento cadastral do munícipe (Nome, endereço, } \\
\text { placa do carro, tipo de residuos e quantidade); Alocação } \\
\text { dos residuos em caçambas e contêineres especificos } \\
\text { (RCC/Nolumosos/Recicláveis). }\end{array}$} & \multicolumn{2}{|c|}{$\begin{array}{l}\text { Alocação de acordo com a tipologia do residuo em caçambas, } \\
\text { baias e recipientes especificos. }\end{array}$} \\
\hline Destino dos RV & \multicolumn{2}{|c|}{$\begin{array}{c}\text { Enviado ao centro de distribuição CDR Pedreira em } \\
\text { Tremembé. }\end{array}$} & \multicolumn{2}{|c|}{$\begin{array}{c}\text { Enviados às empresas de recuperação, valorização e reciclagem. } \\
\text { Os rejeitos para Aterro UTGR Jambeiro. }\end{array}$} \\
\hline $\begin{array}{l}\text { Reutilização, } \\
\text { valorização ou } \\
\text { reciclagem } \\
\text { dos RV }\end{array}$ & \multicolumn{2}{|c|}{$\begin{array}{l}\text { Sem nehnum tipo de aproveitamento. } 100 \% \text { dos } \\
\text { residuos são aterrados. }\end{array}$} & \multicolumn{2}{|c|}{$\begin{array}{l}\text { Sucatas são enviados para reciclagem; Pneus são co- } \\
\text { processados em fornos de cimento; Residuos constituidos de } \\
\text { madeira são triturados e vendidos como combustivel; Envia } \\
\text { espuma de colchões e sofás para reciclagem; Parcerias para } \\
\text { recuperação/valorização de móveis estão em processo de } \\
\text { negociação. }\end{array}$} \\
\hline $\begin{array}{l}\text { Problemas } \\
\text { relatados em } \\
\text { visitas in loco }\end{array}$ & $\begin{array}{l}\text { Munícipes que não atendem } \\
\text { as normas dos ecopontos; } \\
\text { Tentativa de descarte dos } \\
\text { residuos oriundos de } \\
\text { empresas; Mistura de } \\
\text { residuos perigosos junto com } \\
\text { os permitidos; Não poder } \\
\text { receber pneus mesmo } \\
\text { havendo demanda para o } \\
\text { descarte; Dificuldade de } \\
\text { deposição dos RV nas } \\
\text { caçambas altas. }\end{array}$ & $\begin{array}{l}\text { Munícipes que não } \\
\text { atendem as normas dos } \\
\text { ecopontos; Tentativa de } \\
\text { descarte dos residuos } \\
\text { provenientes de } \\
\text { empresas; Mistura de } \\
\text { residuos perigosos junto } \\
\text { com os permitidos; } \\
\text { Dificuldade de deposição } \\
\text { dos RV nas caçambas } \\
\text { altas; Ausência de } \\
\text { valoração dos RV; }\end{array}$ & $\begin{array}{l}\text { Falta de divulgação do } \\
\text { ecoponto; Problemas } \\
\text { estruturais/organização dos } \\
\text { residuos. }\end{array}$ & Falta de divulgação do ecoponto; \\
\hline $\begin{array}{l}\text { Canais de } \\
\text { comunicação }\end{array}$ & \multicolumn{2}{|c|}{$\begin{array}{l}\text { Portal da SOMA, INOVA, AMLURB ou } \\
\text { Prefeitura Municipal. Telefone: } 0800-7777156 .\end{array}$} & \multicolumn{2}{|c|}{$\begin{array}{c}\text { Portal da Prefeitura Municipal, e-mail: svma@pmmc.com.br } \\
\text { Telefone: 4798-5965 }\end{array}$} \\
\hline
\end{tabular}

Figura 1 - Dados sobre o funcionamento/gerenciamento dos resíduos volumosos nos Ecopontos em 2017. Fonte: Elaborado pela autora em 2017.

\section{Ecopontos e Resíduos Volumosos: diretrizes de aperfeiçoamento}

A consulta pública apontou a divulgação e a logística como os principais quesitos a serem melhorados nos Ecopontos. Quanto à divulgação, um importante instrumento para aumentar o conhecimento da população a respeito dos Ecopontos é o meio digital, através de anúncios em redes sociais. Estas informações também podem ser disponibilizadas de forma sistematizada e padronizada nos portais da prefeitura e das empresas vinculadas ao sistema de coleta de resíduos e estes portais podem estar vinculados à aplicativos habilitados para computadores, celulares e tablets. Para a realização e manutenção destes programas é necessária a participação conjunta e de forma contínua e articulada dos agentes públicos e privados, detentores do conhecimento sobre o manejo adequado dos resíduos sólidos. 
Outro método para atingir toda a parcela da sociedade, incluindo os que não fazem uso dos meios digitais, é a elaboração de manuais, cartilhas e panfletos educativos. A distribuição do material impresso para os munícipes podem ocorrer nas instituições de ensino e/ou locais de grande veiculação de pessoas como centros comerciais, parques, estações ferroviárias e terminais de ônibus e metrôs. Os panfletos podem ainda, serem entregues junto com o Imposto Predial e Territorial Urbano (IPTU) e/ou junto com contas de luz, gás e água.

Estes materiais impressos ou online, além de divulgar a localização dos Ecopontos, podem contemplar informações adicionais sobre o funcionamento destes locais, bem como caracterizar os RV, ensinar o correto procedimento de separação destes e evidenciar alguns dos impactos associados ao manejo inadequado destes resíduos. A padronização e sistematização dessas informações permitirá maior clareza e entendimento, evitando informações contraditórias que atualmente geram dúvidas à população. Avisos e atualizações periódicas também colaboram nesse processo de divulgação das informações. Os recursos para estes sistemas de divulgação podem ser provenientes do processo de valorização e reciclagem dos materiais, de taxas como a de coleta de resíduos domiciliares e de Fiscalização dos Serviços de Limpeza Urbana, do Fundo Municipal de Limpeza Urbana, bem como de multas aplicadas na fiscalização de descarte irregular. Um instrumento que também poderia auxiliar na captação de recursos e na educação da população, quanto à geração de RV, seria a cobrança de taxas específicas no ato da compra dos produtos volumosos, estimulando a reflexão para o consumo consciente e a redução da geração de resíduos.

Quanto à logística, ou seja, menor deslocamento para o descarte dos RV se faz necessária a construção de mais Ecopontos no município de São Paulo. Apesar de haver uma projeção de implantação de mais 300 unidades até o ano de 2020 (Prefeitura de São Paulo, 2014), as áreas periféricas do município geralmente não são contempladas. Estas regiões atualmente não contam com unidade de Ecoponto em suas proximidades, no entanto por serem regiões bastante povoadas possuem uma grande demanda de descarte de resíduos. Adicionalmente estas regiões, em geral, abrigam a parcela da população que possui menos recursos de transporte dos resíduos até os Ecopontos. Outra proposição é a criação de Ecopontos móveis onde caçambas provisórias e por tempo determinado podem ser colocadas nas regiões de maior demanda. A demanda pode ser determinada através de um canal de atendimento via telefone e online (aplicativos habilitados para uso via computadores e celulares), na qual o munícipe se cadastra, insere a sua localização e os dados dos resíduos a serem descartados. 0 setor de logística dos Ecopontos pode então localizar as demandas e instalar as caçambas nos pontos provisórios definidos. Dessa forma, é possível recolher os resíduos em quantidade adequada evitando-se onerar o custo de transporte.

As visitas in loco e as entrevistas com gestores apontaram diversos problemas no funcionamento dos Ecopontos. Um dos problemas é o dos munícipes não atenderem as normas do local. Este problema pode ser sanado ou mitigado através da promoção de programas de educação ambiental para a sociedade, de modo a desenvolver maior conscientização sobre o correto manejo destes resíduos e a importância do seu aproveitamento, valorização e reciclagem. Os Programas de educação ambiental poderiam ser realizados dentro dos Ecopontos e/ou através de campanhas de sensibilização da população, promovidos pelos setores públicos e privados. Programas de educação ambiental já são desenvolvidos em alguns países como a Alemanha e Japão, demonstrando um aumento na conscientização e participação da sociedade no equacionamento dos problemas decorrentes da indisposição adequada dos resíduos sólidos. A implantação da educação ambiental, com ênfase nos resíduos sólidos como um programa permanente é um dos objetivos preconizados na PGIRS 2014 (Prefeitura de São Paulo, 2014).

Outra diretriz proposta para incentivar a correta disposição dos RV nos Ecopontos seria a criação de um programa de pontos. Neste programa os munícipes, devidamente cadastrados, ao levarem e disporem corretamente os seus RV nos Ecopontos acumulariam pontos em um cartão. Estes pontos poderiam ser utilizados como desconto nos impostos e tributos municipais e/ou em compras em comércios credenciados. 
Outro problema detectado nos Ecopontos foi o descarte irregular de materiais por grandes geradores e/ou em quantidades superiores a estabelecida $\left(1 \mathrm{~m}^{3}\right)$. Dentro deste contexto poderia haver uma ampliação da capacidade dos Ecopontos, permitindo a entrega de volumes superiores ao citado mediante pagamento de taxas equivalente ao volume de resíduos extra. Estas taxas, sendo inferior ao valor de contratação de caçambas particulares e/ou de serviços terceirizados de remoção de RV, motivaria o munícipe a realizar o transporte dos resíduos até o Ecoponto, evitando o descarte ilegal/indevido no Ecoponto e/ou outro local irregular.

Nas visitas in loco constatou-se também dificuldade por parte do munícipe em depositar seus RV nas caçambas destinada para esta finalidade. Estas caçambas, devido às suas grandes dimensões, possuem altura que dificulta a colocação do RV, especialmente por mulheres, pessoas idosas ou quando o RV é muito pesado. A não existência de um funcionário para auxiliar nesta finalidade inviabiliza ainda mais o procedimento nos casos citados. Dentro deste contexto um equipamento que auxiliasse na deposição destes materiais dentro da caçamba ou um nivelamento da caçamba com o chão (como a construção de rampas que alcancem o nível da caçamba e/ou cavidades no solo para colocação da caçamba) contribuiriam para minimizar o problema. Em relação à infraestrutura e organização dos ecopontos, nos de Mogi das Cruzes foi observada disposição de resíduos sem separação estrutural e alocação em recipientes específicos. Para sanar este problema sugere-se a instalação de contêineres ou caixas organizadoras, como a devida delimitação de espaço, para cada RV. Nos Ecopontos de São Paulo sugere-se uma melhor separação dos resíduos de madeira, proporcionando um melhor aproveitamento deste material.

Nas visitas in loco foram constatadas também a deposição, por parte dos munícipes, de resíduos perigosos (lâmpadas) junto com os RV. Em relação a este descarte irregular, os programas de educação ambiental já descrito anteriormente poderiam auxiliar na conscientização da população quanto à periculosidade e correto manejo destes resíduos. Os Ecopontos poderiam também, abranger a coleta deste material, visando atender a demanda da sociedade e evitar esta deposição irregular junto ao RV e consequentemente aos aterros. Para o destino correto destes resíduos, poderiam ser firmados acordos setoriais entre Ecopontos e os responsáveis pela logística reversa das lâmpadas.

Indica-se medida similar para os pneus, ou seja, de ampliação dos materiais que são coletados pelo Ecoponto. Os pneus, apesar de serem resíduos passíveis de aproveitamento, não são aceitos pela grande maioria dos Ecopontos do município de São Paulo. A destinação final deste RV poderia ser feita através da parceria dos Ecopontos com indústrias que realizam o aproveitamento da borracha em suas atividades, denominado co-processamento (Reciclanip, 2017).

Adicionalmente à todos os problemas citados, ressalta-se a evidência de que $100 \%$ dos RV coletados nos Ecopontos não são reciclados e nem aproveitados. Neste contexto, propõe-se medidas de valorização de alguns RV, que já possuem técnicas e procedimentos de reaproveitamento consolidadas em larga escala, tais como o pneu e a madeira. Os pneus inservíveis, atualmente já são aproveitados pelas indústrias de cimento. Neste processo, a borracha é inserida como uma das matérias-primas da produção do clinquer e/ou como combustível alternativo para o aquecimento dos fornos de cimento. O pneu tem sido aproveitado também, por outros segmentos industriais, tais como a fabricação de asfalto-borracha, manta asfáltica, tapetes para automóveis, solados de sapatos, pisos industriais, borrachas de vedação, pisos para quadras poliesportivas e dutos pluviais (Reciclanip, 2017).

0 reaproveitamento da madeira como material para a produção de bens como, por exemplo, a produção de móveis, peças de design, briquetes ou pellets também é uma estratégia eficiente já empregada em muitos países (Nasrin et al., 2008; Pallavi et al., 2013; Deepak \& Jnanesh, 2015). O Ecodesign e o design sustentável são instrumentos para a valorização dos resíduos de madeira (oriundos de mobiliários) por meio de novas projeções (Silva \& Figueiredo, 2010). A destinação da madeira e dos seus derivados (briquetes e pellets) para combustão com aproveitamento energético também está entre os modelos de gestão mais empregados nos países da União Européia, Estados Unidos e Japão (Jucá et al., 2012). 0 biogás tem sido considerado um relevante subproduto dos tratamentos térmicos de resíduos, uma vez que é uma fonte de produção de calor e eletricidade, além de ser um combustível veicular (Fricke et al., 2015). Estes direcionamentos para a madeira, incluindo o 
aproveitamento energético, além de serem considerados ambientalmente corretos possibilitam ainda a geração de renda ao município, emprego a população, minimiza os desmatamentos e reduz o volume de RV enviado aos aterros sanitários.

Estudos recentes mostram ainda que a cinza de resíduos de madeira (após a caracterização adequada) pode ser usada efetivamente na substituição do cimento durante a produção de concreto com propriedades aceitáveis (Cheah \& Ramli, 2011). As cinzas são aplicadas na produção de materiais e elementos de escada pré-fabricada, briquetes de pavimentação e blocos estruturais pré-moldados. 0 uso na pré-fabricação reduz custos de produção das argamassas de revestimento, demonstrando existir potencial de incentivo, amparada pelas prefeituras municipais na instalação de cooperativas para produção de fábricas deste segmento (Rocha \& Cheriaf, 2003).

Outro RV frequentemente descartado nos Ecopontos e de relevante preocupação para os gestores de serviços de saúde são os colchões. Atualmente técnicas de reciclagem estão disponíveis possibilitando o aproveitamento de $60 \%$ deste RV (Reis et al., 2014). 0 reuso deste resíduo pode ocorrer por meio do processamento da espuma, transformando-as em placas prensadas que são utilizadas em isolamentos térmicos de construções civis ou como forro no assentamento de carpetes (John, 2016).

Em casos de RV passíveis de reutilização como os móveis e os colchões, a criação de um sistema de cadastramento e divulgação destes materiais (sendo de fácil acesso a todos os munícipes) pode estimular a retirada gratuita e o reaproveitamento destes resíduos por lojas de produtos de segunda mão, instituições de caridade, ONGs e pessoas físicas. Ainda é possível ações conjuntas entre a gestão pública e instituições para a valorização dos móveis em condições de recuperação. Projetos sociais de capacitação de cooperados, por meio de oficinas de reformas, demonstram a viabilidade desta direção de aproveitamento (Paróquia Sagrada Família, 2011; Mercatudo Casas André Luiz, 2013). Incentivos fiscais para a comercialização deste tipo de produto seriam adequados ao cenário brasileiro, para estimular o reaproveitamento e valorização destes produtos, além de fomentar o consumo sustentável. Os impostos arrecadados com a comercialização destes resíduos recuperados e/ou valorados podem auxiliar como fundo de fomento dos programas de educação ambiental, assim como na manutenção e melhorias dos Ecopontos.

\section{Indicadores para as diretrizes de aperfeiçoamento propostas}

Os indicadores são instrumentos utilizados para capturar as tendências dos padrões e/ou das alterações de padrões, visando orientar os agentes tomadores de decisão durante a aplicação e o monitoramento de políticas e estratégias. Com o objetivo de estabelecer metas e verificar a eficácia das ações propostas alguns indicadores foram estabelecidos (Quadro 1). Estes indicadores foram criados com base em indicadores para desempenho ambiental descritos em literatura (Campos \& Melo, 2008), adaptando-os para as especificidades dos RV e Ecopontos.

Quadro 1 - Diretrizes e indicadores de desenvolvimento ambiental para as proposições de gerenciamento de RV elaboradas neste trabalho

\begin{tabular}{|c|c|}
\hline Diretrizes & Indicadores \\
\hline $\begin{array}{c}\text { Projetos de divulgação: } \\
\text { cartilhas, manuais e } \\
\text { panfletos. }\end{array}$ & 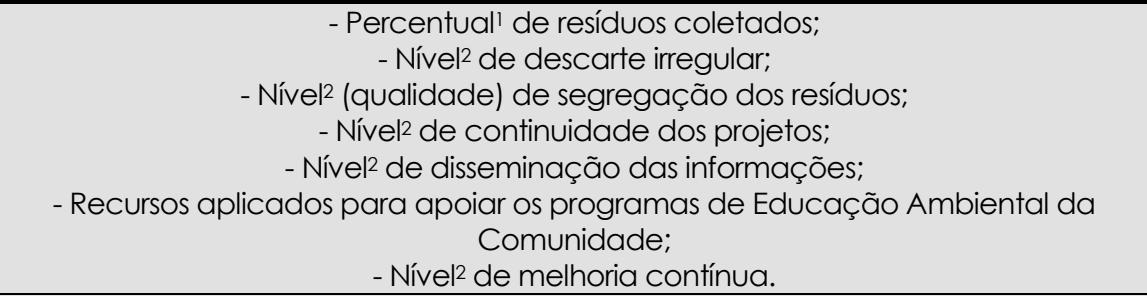 \\
\hline $\begin{array}{l}\text { Projetos de divulgação: } \\
\text { cartilhas, manuais e } \\
\text { panfletos. }\end{array}$ & $\begin{array}{l}\text { - Número de programas/materiais fornecidos à comunidade; } \\
\text { - Nível2 de conscientização da população (aferir por meio de consultas públicas); }\end{array}$ \\
\hline Programa Ecoponto-móveis & - Percentual' de resíduos coletados por este meio; \\
\hline
\end{tabular}


Quadro 1 - Continuação...

\begin{tabular}{|c|c|}
\hline Diretrizes & Indicadores \\
\hline $\begin{array}{c}\text { e Implantação de novos } \\
\text { Ecopontos }\end{array}$ & $\begin{array}{c}\text { - Taxa }{ }^{3} \text { de recuperação dos resíduos; } \\
\text { - Nível2 de descarte irregular no entorno; } \\
\text { - Nível2 de disseminação das informações; } \\
\text { - Nível2 de conhecimento obtido pós-divulgação; } \\
\text { - Nível2 de satisfação; } \\
\text { - Número de munícipes atendidos }{ }^{4} \text {. }\end{array}$ \\
\hline $\begin{array}{c}\text { Programas de Educação } \\
\text { ambiental }\end{array}$ & $\begin{array}{c}\text { - Percentual' de resíduos coletados; } \\
\text { - Nível2 de descarte irregular; } \\
\text { - Nível2 (qualidade) de segregação dos resíduos; } \\
\text { - Nível2 de conhecimento obtido pós-treinamento; } \\
\text { - Nível2 de continuidade dos programas; } \\
\text { Comunidade; } \\
\text { - Recursos }{ }^{5} \text { aplicados para apoiar os programas de Educação Ambiental da } \\
\text { - Número de programas/materiais fornecidos; } \\
\text { - Nível2 de disseminação das informações; } \\
\text { - Nível'2 de conscientização da melhoria contínua; } \\
\text { - Taxa }{ }^{3} \text { de recuperação dos resíduos; } \\
\text { - Nível2 de satisfação dos funcionários dos Ecopontos; } \\
\text { - Nível2 de satisfação da população. }\end{array}$ \\
\hline Programa Cartão de Pontos & $\begin{array}{c}\text { - Número de parcerias público-privado; } \\
\text { - Número de aderidos ao programa; } \\
\text { - Quantidadé de resíduos coletados com o programa; } \\
\text { - Nível2 de satisfação da população; } \\
\text { - Taxa }{ }^{3} \text { de recuperação dos resíduos; } \\
\text { - Tempo de continuidade da atividade comercial. }\end{array}$ \\
\hline $\begin{array}{l}\text { Ampliação da capacidade } \\
\text { de descarte através da } \\
\text { captação de tributos }\end{array}$ & $\begin{array}{l}\text { - Percentual' de resíduos coletados; } \\
\text { - Nível2 de descarte irregular no entorno; } \\
\text { - Montante de recursos obtidos pela adesão da taxa; } \\
\text { - Nível }{ }^{2} \text { de satisfação da população. }\end{array}$ \\
\hline $\begin{array}{c}\text { Infraestrutura e técnicas de } \\
\text { facilitação para descarte } \\
\text { nas caçambas }\end{array}$ & $\begin{array}{l}\text { - Nível }{ }^{2} \text { de satisfação da população; } \\
\text { - Nível2 de satisfação dos funcionários; } \\
\text { - Nível2 de dificuldade para o descarte; }\end{array}$ \\
\hline $\begin{array}{l}\text { Instalação de } \\
\text { armazenadores específicos } \\
\text { (Ecopontos Mogi das } \\
\text { Cruzes) e segregação de } \\
\text { madeira (Ecopontos de São } \\
\text { Paulo) }\end{array}$ & $\begin{array}{l}\text { - Percentual' de resíduos coletados; } \\
\text { - Nível2 (qualidade) de segregação dos resíduos; } \\
\text { - Taxa }{ }^{3} \text { de recuperação dos resíduos; } \\
\text { - Nível2 }{ }^{2} \text { de organização nos Ecopontos. }\end{array}$ \\
\hline $\begin{array}{l}\text { Ampliação das tipologias } \\
\text { coletadas nos Ecopontos: } \\
\text { lâmpadas e pneus }\end{array}$ & $\begin{array}{l}\text { - Número de resíduos coletados com o programa; } \\
\text { - Nível2 de satisfação da população; } \\
\text { - Nível2 de dificuldade para o descarte; } \\
\text { - } \text { Taxa }^{3} \text { de recuperação dos resíduos. }\end{array}$ \\
\hline $\begin{array}{l}\text { Estabelecimento de } \\
\text { procedimentos de } \\
\text { Valorização dos RV }\end{array}$ & $\begin{array}{l}\text { - Percentual' de resíduos coletados } \\
\text { - Taxa } \text { de recuperação dos resíduos; } \\
\text { - Nível2 (qualidade) de segregação dos resíduos; } \\
\text { - Montante de recursos obtidos pela valorização; } \\
\text { - Número de parcerias público-privado; } \\
\text { - Quantidade6 de rejeitos. }\end{array}$ \\
\hline
\end{tabular}

1 Para o indicador percentual de resíduos coletados inserir fator de correção considerando variáveis como aumento da população da região, média de resíduos gerados por pessoa. ${ }^{2}$ Para o termo nível, avaliar estipulando metas para o intervalo dos seguintes parâmetros: (I) B - Baixo nível; (II) M - Médio nível; (III) A - Alto nível. ${ }^{3}$ A taxa de recuperação de resíduos é obtida pela razão (Quantidade de material recuperado / Quantidade total de resíduos dispostos). ${ }^{4} \mathrm{O}$ número de munícipes atendidos é pela razão da área compreendida. 5 Recursos aplicados são os investimentos financeiros realizado para apoiar objetivos específicos. 6 O termo quantidade faz referência ao peso. Fonte: Elaborado pela autora em 2017.

\section{Considerações finais}

Conclui-se que as principais dificuldades enfrentadas pela população do município de São Paulo quanto ao descarte de RV são a falta de divulgação e a logística dos Ecopontos. Sobre a rotina de funcionamento e gerenciamento dos Ecopontos, diversas falhas são existentes e podem ser 
aprimoradas, tais como a falta de comprometimento dos munícipes quanto às normas dos Ecopontos, problemas estruturais/organizacionais nos Ecopontos e a ausência de aproveitamento e valorização desses resíduos.

De acordo com as diretrizes e indicadores propostos, medidas focadas na redução do volume dos RV por meio de sua recuperação como matéria prima reutilizável, conjuntamente com atividades de educação ambiental (objetivando a redução do consumo, a reutilização e recuperação por parte dos munícipes), podem contribuir para estabelecer um gerenciamento de RV no município de São Paulo de forma sustentável e com benefícios socioambientais.

\section{Referências}

Adorno, R. C. F., \& Castro, A. L (1994). 0 exercício da sensibilidade: pesquisa qualitativa e a saúde como qualidade. Saúde e Sociedade, 3(2), 172-185. http://dx.doi.org/10.1590/S0104-12901994000200009.

Associação Brasileira de Empresas de Limpeza Pública e Resíduos Especiais - ABRELPE (2016). Panorama dos Resíduos Sólidos no Brasil - 2016. São Paulo: ABRELPE. Recuperado em 24 de junho de 2018, de www.abrelpe.org.br/panorama

Associação Brasileira de Normas Técnicas - ABNT (2004). Classificação de Resíduos Sólidos - Norma ABNT NBR 10.004:2004. Rio de Janeiro: ABNT. Recuperado em 24 de junho de 2018, de http://www.unaerp.br/documentos/2234-abnt-nbr-10004/file

Autoridade Municipal de Limpeza Urbana - AMLURB (2017). Ecoponto: estação de entrega voluntária de inservíveis. São Paulo: AMLURB. Recuperado em 24 de junho de 2018, de http://www.prefeitura.sp.gov.br/cidade/secretarias/regionais/amlurb/ecopontos/index.php?p=4626

Brasil. (2002, 17 de julho). Resolução n. 307, de 5 de julho de 2002. Estabelece as Diretrizes, Critérios e Procedimentos para a Gestão dos Resíduos da Construção Civil. Brasília: Diário Oficial da União, seção 1.

Brasil. (2010, 3 de agosto). Lei n. 12.305, de 2 de agosto de 2010. Institui a Política Nacional de Resíduos Sólidos; altera a Lei no 9.605, de 12 de fevereiro de 1998, e dá outras providências. Brasília: Diário Oficial da União, seção 1.

Brasil. (2016, 7 de abril). Resolução n. 510, de 7 de abril de 2016. Dispõe sobre as normas aplicáveis a pesquisas em Ciências Humanas e Sociais cujos procedimentos metodológicos envolvam a utilização de dados diretamente obtidos com os participantes ou de informações identificáveis ou que possam acarretar riscos maiores do que os existentes na vida cotidiana, na forma definida nesta Resolução. Brasília: Diário Oficial da União, seção 1.

Boni, V., \& Quaresma, S. J. (2005). Aprendendo a entrevistar: como fazer entrevistas em Ciências Sociais. Tese, 2(1), 68-80. http://dx.doi.org/10.5007/\%25x.

Campos, L. M. S., \& Melo, D. A. (2008). Indicadores de desempenho dos Sistemas de Gestão Ambiental (SGA): uma pesquisa teórica. Production, 18(3), 540-555. http://dx.doi.org/10.1590/S0103-65132008000300010.

Cheah, C. B., \& Ramli, M. (2011). The implementation of wood waste ash as a partial cement replacement material in the production of structural grade concrete and mortar: an overview. Resources, Conservation and Recycling, 55(7), 669-685. http://dx.doi.org/10.1016/j.resconrec.2011.02.002.

Deepak, K. B., \& Jnanesh, N. A. (2015). Investigation of Areca Leaves as a Biomass Fuel by the Method of Briquetting. International Journal of Mechanical Engineering, 3(7), 16-21.

European Environment Agency - EEA (2009). Diverting waste from landfill: effectiveness of waste management policies in the European Union. (Vol. 7). Copenhagen: EEA.

Fernandez, J. A. B. (2012). Diagnóstico dos resíduos sólidos da construção civil. Brasília: Instituto de Pesquisa Econômica Aplicada.

Ferreira, J. A., \& Anjos, L. A. (2001). Aspectos de saúde coletiva e ocupacional associados à gestão dos resíduos sólidos municipais. Cadernos de Saude Publica, 17(3), 689-696. http://dx.doi.org/10.1590/S0102-

311X2001000300023. PMid:11395805. 
Fricke, K., Pereira, C., Leite, A., \& Bagnati, M. (2015). Gestão sustentável de resíduos sólidos urbanos: transferência de experiência entre a Alemanha e o Brasil. Braunschweig: Technische Universität Braunschweig.

Giusti, L. (2009). A review of waste management practices and their impact on human health. Waste Management, 29(8), 2227-2239. http://dx.doi.org/10.1016/j.wasman.2009.03.028. PMid:19401266.

Gouveia, N. (2012). Resíduos sólidos urbanos: impactos socioambientais e perspectiva de manejo sustentável com inclusão social. Ciencia \& Saude Coletiva, 17(6), 1503-1510. http://dx.doi.org/10.1590/S1413-

81232012000600014. PMid:22699641.

Inova. (2017). Coleta de entulho e volumosos. São Paulo: INOVA. Recuperado em 26 de junho de 2018, de http://www.inovagsu.com.br/o-que-fazemos/coleta-de-entulho

Jacobi, P. R., \& Besen, G. R. (2006). Gestão de resíduos sólidos na região metropolitana de São Paulo. São Paulo em Perspectiva, 20(2), 90-104.

Jacobi, P. R., \& Besen, G. R. (2011). Gestão de resíduos sólidos em São Paulo: desafios da sustentabilidade. Estudos Avançados, 25(71), 135-158. http://dx.doi.org/10.1590/S0103-40142011000100010.

Jaron, A., \& Kossmann, C. (2018). Waste Management in Germany: Facts, data, diagrams. Berlin: Federal Ministry for the Environment, Nature Conservation and Nuclear Safety.

John, L. (2016). Colchão velho, novo isolante. Recuperado em 24 de junho de 2018, de http://conexaoplaneta.com.br/blog/colchao-velho-novo-isolante/

Jucá, J. F. T., Lima, J. D., Mariano, M. O. H., Firmo, A. L. B., Lima, D. G. A., Lucena, L. F. L., Farias, P. R. R., Junior, F. H. C., Carvalho, E. H., Ferreira, J. A., \& Reichert, G. A. (2012). Análise das diversas tecnologias de tratamento e disposição final de resíduos sólidos urbanos no Brasil, Europa, Estados Unidos e Japão. Recife: FADE-UFPE.

Karpinsk, L. A., Pandolfo, A., Reineher, R., Kurek, J., Pandolfo, L. M., \& Guimarães, J. C. B. (2009). Gestão diferenciada de resíduos da construção civil: Uma abordagem ambiental. Porto Alegre: Edipucrs.

May, T. (2001). Social research: issues, methods and process. New York: Open University Press.

Mercatudo Casas André Luiz (2013). Sua doação faz toda a diferença! Guarulhos: Mercatudo. Recuperado em 24 de junho de 2018, de http://mercatudo.org.br/index.php

Milanez, B. (2002). Resíduos sólidos e sustentabilidade: princípios, indicadores e instrumentos de ação (Dissertação de Mestrado). Programa de Pós-graduação em Engenharia Urbana, Universidade Federal de São Carlos, São Carlos.

Ministério do Meio Ambiente - MMA (2017). Política Nacional de Resíduos Sólidos. Brasília: MMA. Recuperado em 24 de junho de 2018, de http://www.mma.gov.br/cidades- sustentaveis/residuos-solidos/politica-nacional-deresiduos-solidos

Nasrin, A. B., Ma, A. N., Choo, Y. M., Mohamad, S., Rohaya, M. H., Azali, A., \& Zainal, Z. (2008). Oil palm biomass as potential substitution raw materials for commercial biomass briquettes production. American Journal of Applied Sciences, 5(3), 179-183. http://dx.doi.org/10.3844/ajassp.2008.179.183.

Pallavi, H. V., Srikantaswamy, S., Kiran, B. M., Vyshnavi, D. R., \& Ashwin, C. A. (2013). Briquetting agricultural waste as an energy source. Journal of Environmental Science. Computer Science and Engineering \& Technology, 2(1), 160172.

Paróquia Sagrada Família (2011). Cáritas Diocesana promove bazar beneficente. São José dos Campos: Paróquia Sagrada Família. Recuperado em 26 de junho de 2018, de http://www.sagradafamiliaonline.org.br/noticias.php?id=429\#.WhBLtyMrJcw

Pinhel, J. R. (2013). Do lixo à cidadania: guia para a formação de cooperativas de catadores de materiais recicláveis. São Paulo: Editora Peirópolis.

Pinto, T. P. (1999). Metodologia para gestão diferenciada de resíduos sólidos da construção urbana (Tese de Doutorado). Escola Politécnica, Universidade de São Paulo, São Paulo. 
Polaz, C. N. M., \& Teixeira, B. A. N. (2009). Indicadores de sustentabilidade para a gestão municipal de resíduos sólidos urbanos: um estudo para São Carlos (SP). Engenharia Sanitaria e Ambiental, 14(3), 411-420.

http://dx.doi.org/10.1590/S1413-41522009000300015.

Prefeitura de São Paulo (2014). Plano de Gestão Integrada de Resíduos Sólidos da Cidade de São Paulo. São Paulo: Prefeitura de São Paulo. Recuperado em 24 de junho de 2018, de http://www.prefeitura.sp.gov.br/cidade/secretarias/upload/servicos/arquivos/PGIRS-2014.pdf

Reciclanip. (2017). O ciclo sustentável do pneu. São Paulo: Reciclanip. Recuperado em 24 de junho de 2018, de http://www.reciclanip.com.br/v3/quem-somos-institucional

Reis, G. A. X., Rossaneis, M. A., Haddad, M. C. L., \& Belei, R. A. (2014). Critérios para aquisição, conservação e descarte de colchões em instituições de saúde. Revista Mineira de Enfermagem, 8(3), 673-678.

Rocha, J. C., \& Cheriaf, M. (2003). Aproveitamento de resíduos na construção. Coletânea Habitare, 4, 72-93.

Rudio, F. V. (2001). Introdução ao projeto de pesquisa científica (29a ed.). Petrópolis: Vozes.

São Paulo. (2008, 27 de junho). Lei n. 14.803, de 26 de junho de 2008. Dispõe sobre o Plano Integrado de Gerenciamento dos Resíduos da Construção Civil e Resíduos Volumosos e seus componentes. São Paulo: Diário Oficial do Município, número 118.

São Paulo. (2014, 16 de maio). Decreto n. 55.113, de 15 de maio de 2014. Dispõe sobre a implantação de Ecopontos no Município de São Paulo. São Paulo: Diário Oficial do Município, número 90.

Silva, A. F., \& Figueiredo, C. F. (2010). Reaproveitamento de resíduos de MDF da indústria moveleira. Design e Tecnologia, 1(2), 77-87. http://dx.doi.org/10.23972/det2010iss02pp77-87.

Silva, D. P. (2016). Avaliação do processo de adensamento de resíduos de poda de árvore visando ao aproveitamento energético: o caso do campus da USP na capital (Dissertação de mestrado). Instituto de Energia e Ambiente, Universidade de São Paulo, São Paulo.

Soluções em Meio Ambiente - SOMA (2013). Ecopontos Soma. São Paulo: SOMA. Recuperado em 24 de junho de 2018, de http://www.consorciosoma.com.br/ecopontos-soma

Yolin, C. (2015). Waste Management and Recycling in Japan Opportunities for European Companies (SMEs Focus). Tokyo: EU-Japan Center for Industrial Cooperation.

Editor: Harry Bollmann

Recebido: Dez. 14, 2018

Aceito: Mar. 19, 2019 


\section{Apêndice A - Questionário aplicado para consulta pública sobre Ecoponto}

\section{Questionário - ECOPONTO}

* Aluno, docente e/ou funcionário da EACH-USP? Sim ( ) Não ( )

*Homem ( ) Mulher ( )

* Idade:

* Profissão:

Por favor, marque com $\mathrm{X}$ para resposta SIM ou NÃO em frente à pergunta correspondente

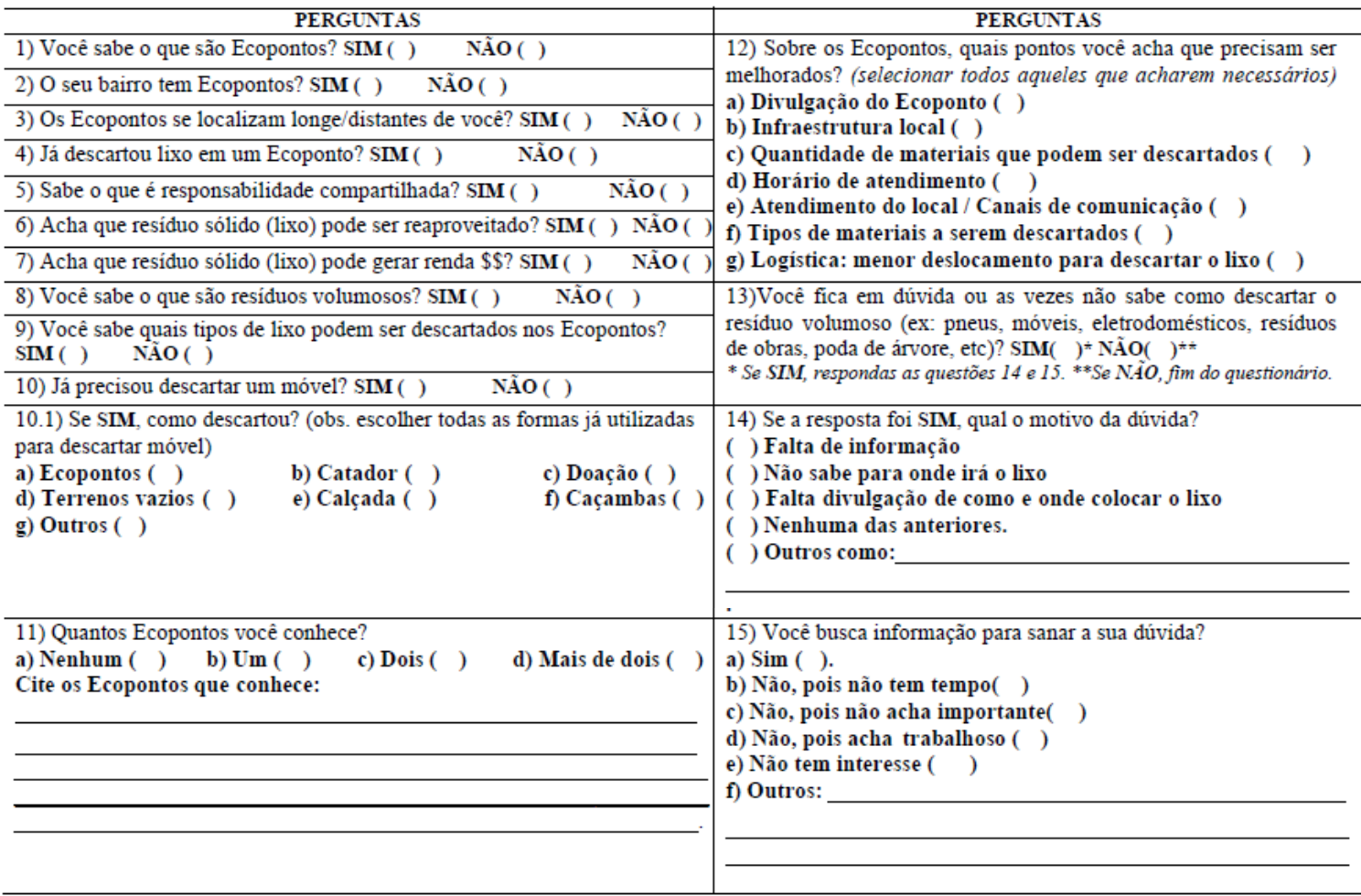

*** Caso seja de interesse, abaixo encontra-se a descrição de alguns termos. $\rightarrow$ \# Essa informação foi útil? SIM( ) NÃo ( )

Ecopontos: são locais que o munícipe pode entregar gratuitamente resíduos recicláveis, pequenos volumes de entulho com limite até $1 \mathrm{~m}^{3}$ e objetos de grandes dimensões (residuos volumosos), tais como móveis, pneus, galhos provenientes de poda de árvores, eletrodomésticos e outros. Residuos Volumosos: são objetos de grandes dimensões constituídos basicamente por entulhos de construção (volume de entrega no ecoponto limitado a $1 \mathrm{~m}^{3}$ por dia para o mesmo endereço), madeiras (residuos de podas e outras), móveis, pneus e eletrodomésticos. Estes residuos não são transportados pela coleta pública municipal de rotina e seu descarte irregular pode causar graves problemas ambientais e riscos à saúde pública (ex: enchentes; contaminação do solo, água e ar; proliferação de vetores e agentes transmissores de doenças, entre outros). Responsabilidade Compartilhada: de acordo com a lei de Política Nacional de Resíduos Sólidos, todos os cidadãos e cidadãs, assim como as indústrias, o comércio, o setor de serviços e ainda as instâncias do poder público terão cada qual uma parte da responsabilidade pelos resíduos sólidos (lixo) gerados, além de serem responsáveis pelo ciclo de vida dos produtos. A lei busca melhorar a gestão dos resíduos sólidos com base na divisão das responsabilidades entre a sociedade, o poder público e a iniciativa privada.

\section{Muitíssimo obrigada por sua participação e colaboração nesta pesquisa!!!}

O espaço abaixo e o verso desta folha é destinado para você escrever opiniões/apontamentos, reclamações e sugestões sobre os Ecopontos. (Não se preocupe em responder, pois estes dados serão mantidos em sigilo, sendo usados somente para fins da pesquisa) 